\title{
Effects of Ce Addition on High Temperature Deformation Behavior of Cu-Cr-Zr Alloys
}

\author{
Yi Zhang, Alex A. Volinsky, Hai T. Tran, Zhe Chai, Ping Liu, and Baohong Tian
}

(Submitted April 17, 2015; in revised form August 15, 2015; published online September 3, 2015)

\begin{abstract}
Hot deformation behavior of the $\mathrm{Cu}-\mathrm{Cr}-\mathrm{Zr}$ and $\mathrm{Cu}-\mathrm{Cr}-\mathrm{Zr}-\mathrm{Ce}$ alloys was investigated by compressive tests using the Glee-ble-1500D thermomechanical simulator at $650-850{ }^{\circ} \mathrm{C}$ and $0.001-10 \mathrm{~s}^{-1}$ strain rate. The flow stress decreased with the deformation temperature at a given stain rate. However, the flow stress increased with the strain rate at the same deformation temperature. The constitutive equations for two kinds of alloys were obtained by correlating the flow stress, the strain rate and temperature using stepwise regression analysis. The addition of $\mathrm{Ce}$ can refine the grain and effectively accelerate dynamic recrystallization. The processing maps were established, based on the dynamic material model. Instability zones in the flow behavior can be easily recognized. Hot deformation optimal processing parameters were obtained in the range of this experiment. The hot deformation characteristics and microstructure were also analyzed by the processing maps. The addition of $\mathrm{Ce}$ can optimize hot workability of the $\mathrm{Cu}-\mathrm{Cr}-\mathrm{Zr}$ alloy.
\end{abstract}

Keywords constitutive equations, $\mathrm{Cu}-\mathrm{Cr}-\mathrm{Zr}-\mathrm{Ce}$ alloy, heat treatment, high temperature deformation, processing maps, thermomechanical processing

\section{Introduction}

Copper alloys are widely used in electronics due to high strength and good electrical conductivity (Ref 1-5). The lead frame is important for microelectronics, since it is a foundation of the integrated circuit, supporting the chip, transmitting electric signals, and radiating generated heat. The lead frame material should have adequate electrical and heat conductivity, high strength and heat resistance, and excellent processing properties (Ref 6-8). Because of the high electrical conductivity, $\mathrm{Cu}$ alloys have been widely used as the lead frame material, including $\mathrm{Cu}-\mathrm{Ni}-\mathrm{Si}, \mathrm{Cu}-\mathrm{Fe}, \mathrm{Cu}-\mathrm{Fe}-\mathrm{P}, \mathrm{Cu}-\mathrm{Cr}-\mathrm{Zr}, \mathrm{Cu}-\mathrm{Ag}$, and others. Among these, the $\mathrm{Cu}-\mathrm{Cr}-\mathrm{Zr}$ alloy has become a research focus due to its high strength and hardness, good processing properties and electrical conductivity (Ref 9-15).

Yi Zhang, College of Materials Science and Engineering, Henan University of Science and Technology, Luoyang 471003, China; Department of Mechanical Engineering, University of South Florida, Tampa 33620 and Collaborative Innovation Center of Nonferrous Metals, Henan Province, Luoyang 471003, China; Alex A. Volinsky and Hai T. Tran, Department of Mechanical Engineering, University of South Florida, Tampa 33620; Zhe Chai, College of Materials Science and Engineering, Henan University of Science and Technology, Luoyang 471003, China and College of Materials Science and Engineering, University of Shanghai for Science and Technology, Shanghai 200093, China; Ping Liu, College of Materials Science and Engineering, University of Shanghai for Science and Technology, Shanghai 200093, China; and Baohong Tian, College of Materials Science and Engineering, Henan University of Science and Technology, Luoyang 471003, China and Collaborative Innovation Center of Nonferrous Metals, Henan Province, Luoyang 471003, China. Contact e-mails: zhshgu436@163.com and volinsky@usf.edu.

In this study, the effects of deformation parameters, including temperature and strain rate on the flow stress of the $\mathrm{Cu}-\mathrm{Cr}-\mathrm{Zr}$ and $\mathrm{Cu}-\mathrm{Cr}-\mathrm{Zr}-\mathrm{Ce}$ alloys have been investigated by hot compression tests. The constitutive constants of the two alloys have been determined, and constitutive equations, relating the Zener-Hollomon $Z$ parameter, hot deformation activation energy, $Q$, and processing maps have been derived. The effects of deformation parameters on the microstructure evolution during hot deformation have been also studied in detail. This study optimized the hot deformation processing parameters for manufacturing lead frame strips with desirable microstructure.

\section{Experimental Details}

The experimental alloy was melted in a vacuum induction furnace under argon atmosphere, using cathode copper, pure chrome, pure spongy zirconium, and pure cerium, and then cast into a low carbon steel mold with $\Phi 83 \mathrm{~mm} \times 150 \mathrm{~mm}$ dimensions. Its chemical composition in wt.\% is $0.4 \mathrm{Cr}$, $0.15 \mathrm{Zr}, 0.05 \mathrm{Ce}$, and $\mathrm{Cu}$ balance. The ingot was homogenized at $930{ }^{\circ} \mathrm{C}$ for $2 \mathrm{~h}$ to remove the alloying elements segregation. Subsequently, the ingot was forged into $25 \mathrm{~mm}$ diameter bars. Finally, the forged bars were solution-treated at $900{ }^{\circ} \mathrm{C}$ for $1 \mathrm{~h}$, followed by water quenching.

Cylindrical compression specimens with $8 \mathrm{~mm}$ diameter and $12 \mathrm{~mm}$ high were machined from the solution-treated bars. The hot compression tests were carried out on the Gleeble-1500D thermomechanical simulator at a strain rate of $0.001-10 \mathrm{~s}^{-1}$ and deformation temperature of $650-850{ }^{\circ} \mathrm{C}$. The specimens were heated to the deformation temperature at $5{ }^{\circ} \mathrm{C} / \mathrm{s}$ heating rate. Before deformation, all specimens were kept at the deformation temperature for $180 \mathrm{~s}$. All specimens were compressed to a true strain of 0.6. The yield stress standard deviation for the performed measurements was $\pm 3 \mathrm{MPa}$. The standard deviation meets the ASTM-E8 standard and the error bars for the yield stress are less than $\pm 1.5 \%$. For the same material and conditions 50 compression tests were performed on the 

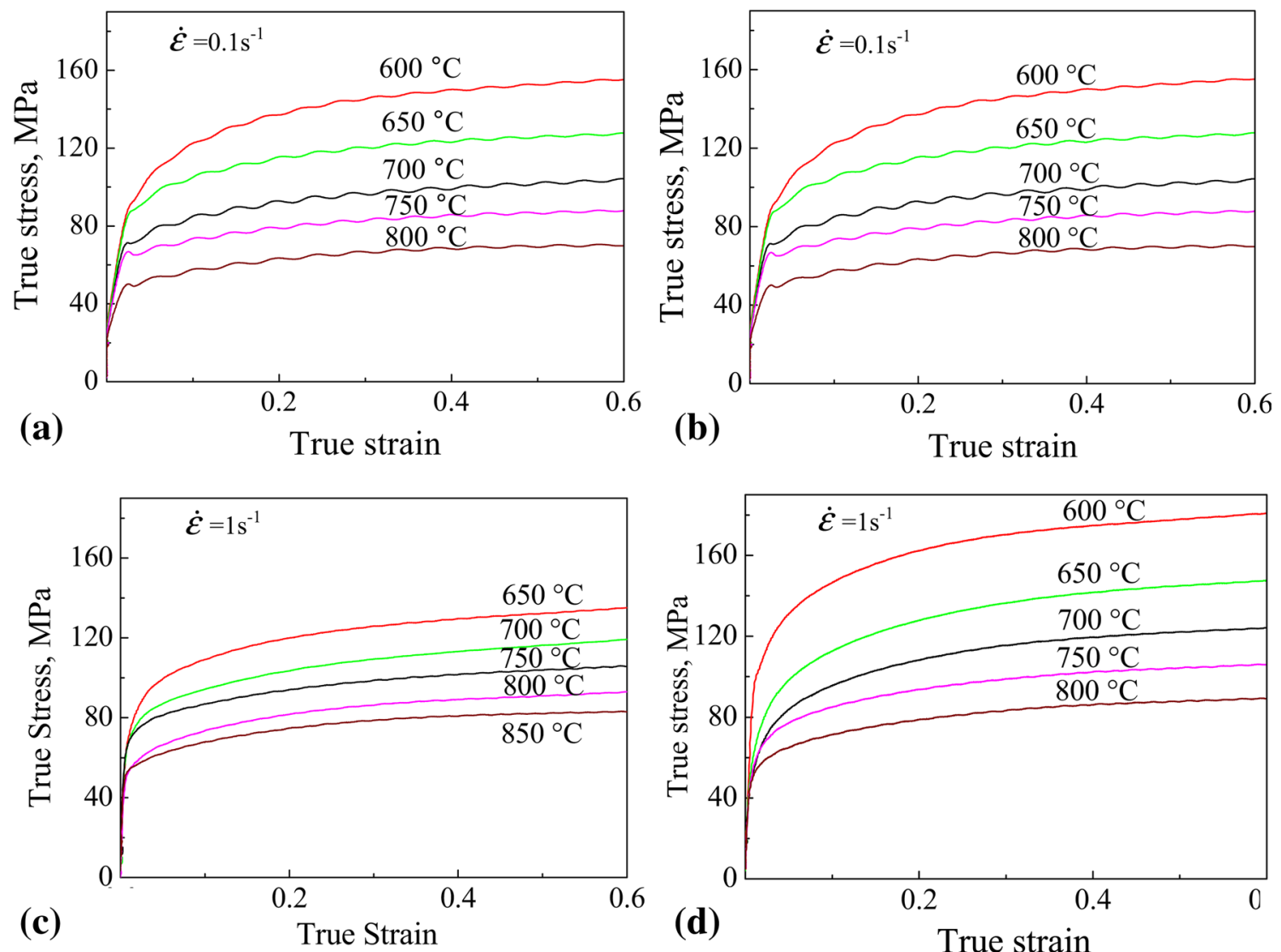

Fig. 1 True stress-strain curves of $(\mathrm{a}, \mathrm{c}) \mathrm{Cu}-0.4 \mathrm{Cr}-0.15 \mathrm{Zr}$ and $(\mathrm{b}, \mathrm{d}) \mathrm{Cu}-0.4 \mathrm{Cr}-0.15 \mathrm{Zr}-0.05 \mathrm{Ce}$ alloys at different hot compression temperature and strain rate: $(\mathrm{a}, \mathrm{b}) \dot{\varepsilon}=0.1 \mathrm{~s}^{-1} ;(\mathrm{c}, \mathrm{d}) \dot{\varepsilon}=1 \mathrm{~s}^{-1}$. The measured yield stress standard deviation is $\pm 3 \mathrm{MPa}$

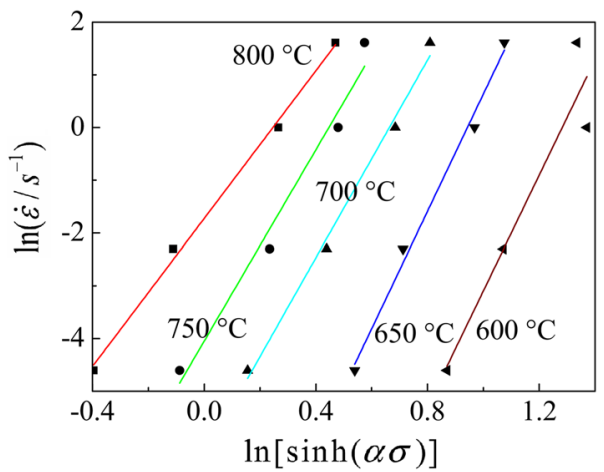

Fig. 2 Relationship between the Cu-Cr-Zr-Ce alloy peak stress and the strain rate at different temperatures. Error bars are smaller than the symbols size

Gleeble-1500D thermomechanical simulator. After compression testing, the specimens were immediately quenched by water. The deformed specimens were sectioned through the longitudinal axis. Specimens were polished and then etched. The microstructure was observed using OLYMPUS PMG3 optical microscope. Calculations of the grain size were performed using the SISCA software. The measurement method meets the ASTM-E112-96 (2004) standard. The grain size was measured using at least ten different areas of each sample. At least five samples were measured for each alloy.

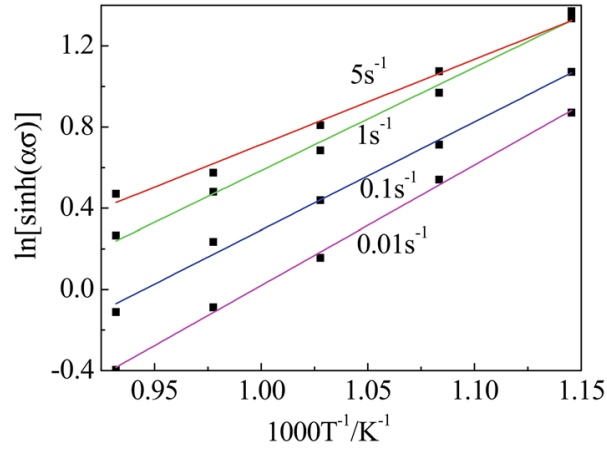

Fig. 3 Relationship between the $\mathrm{Cu}-\mathrm{Cr}-\mathrm{Zr}-\mathrm{Ce}$ alloy peak stress and temperature. Error bars are smaller than the symbols size

\section{Results and Discussion}

\subsection{True Stress-Strain Curves}

The stress-strain behavior of the $\mathrm{Cu}-\mathrm{Cr}-\mathrm{Zr}$ and $\mathrm{Cu}-\mathrm{Cr}-\mathrm{Zr}-\mathrm{Ce}$ alloys at different deformation temperature and different strain rates is shown in Fig. 1. The deformation temperature and the strain rate affected the alloy flow behavior. The flow stress decreased with the deformation temperature at a given stain rate, while the flow stress increased with the strain rate at the same deformation temperature. 
Comparing the stress-strain curves of the $\mathrm{Cu}-\mathrm{Cr}-\mathrm{Zr}$ and $\mathrm{Cu}-$ $\mathrm{Cr}-\mathrm{Zr}-\mathrm{Ce}$ alloys, the addition of Ce improves the peak stress of the $\mathrm{Cu}-\mathrm{Cr}-\mathrm{Zr}$ alloy during hot deformation. The peak stress increased by $5 \%$ and $3.5 \%$ when deformed with the strain rate

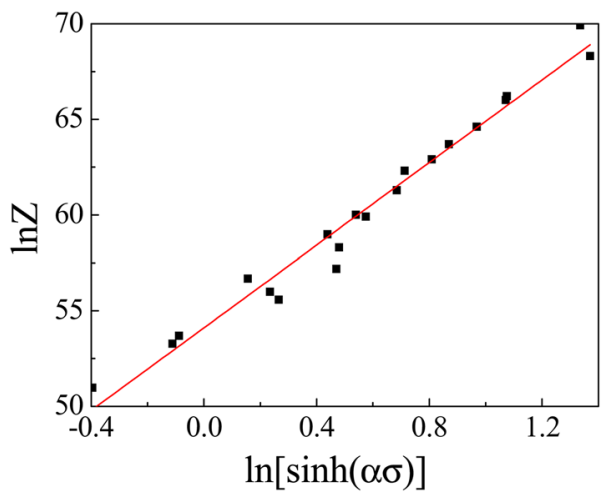

Fig. 4 Relationship between the $\mathrm{Cu}-\mathrm{Cr}-\mathrm{Zr}$-Ce alloy peak stress and the Zener-Hollomon parameter. Error bars are smaller than the symbols size of $1 \mathrm{~s}^{-1}$ at 650 and $750{ }^{\circ} \mathrm{C}$, respectively. Since the rare earth elements can effectively fix dislocations, $\mathrm{Ce}$ addition can improve deformation resistance of the $\mathrm{Cu}-\mathrm{Cr}-\mathrm{Zr}$ alloy.

\subsection{Constitutive Analysis}

Arrhenius equation is widely used to describe relationships between the strain rate, the flow stress, and temperature (Ref 16-18). The equation can be written as

$\dot{\varepsilon}=A\left[\sinh \left(\alpha \cdot \sigma_{\mathrm{P}}\right)\right]^{n} \exp \left(-Q_{R T}\right)$,

where $\dot{\varepsilon}$ is the strain rate, $T$ is the absolute temperature, $\sigma_{\mathrm{P}}$ is generally taken as the peak stress, $R$ is the gas constant, $Q$ is the activation energy for hot deformation, while $A, n$ and $\alpha$ are materials constants.

Equation 1 can be conveniently expressed in terms of the temperature-compensated strain rate factor, the Zener-Hollomon parameter $\mathrm{Z}$ :

$Z=\dot{\varepsilon} \exp \left(\frac{Q}{R T}\right)$
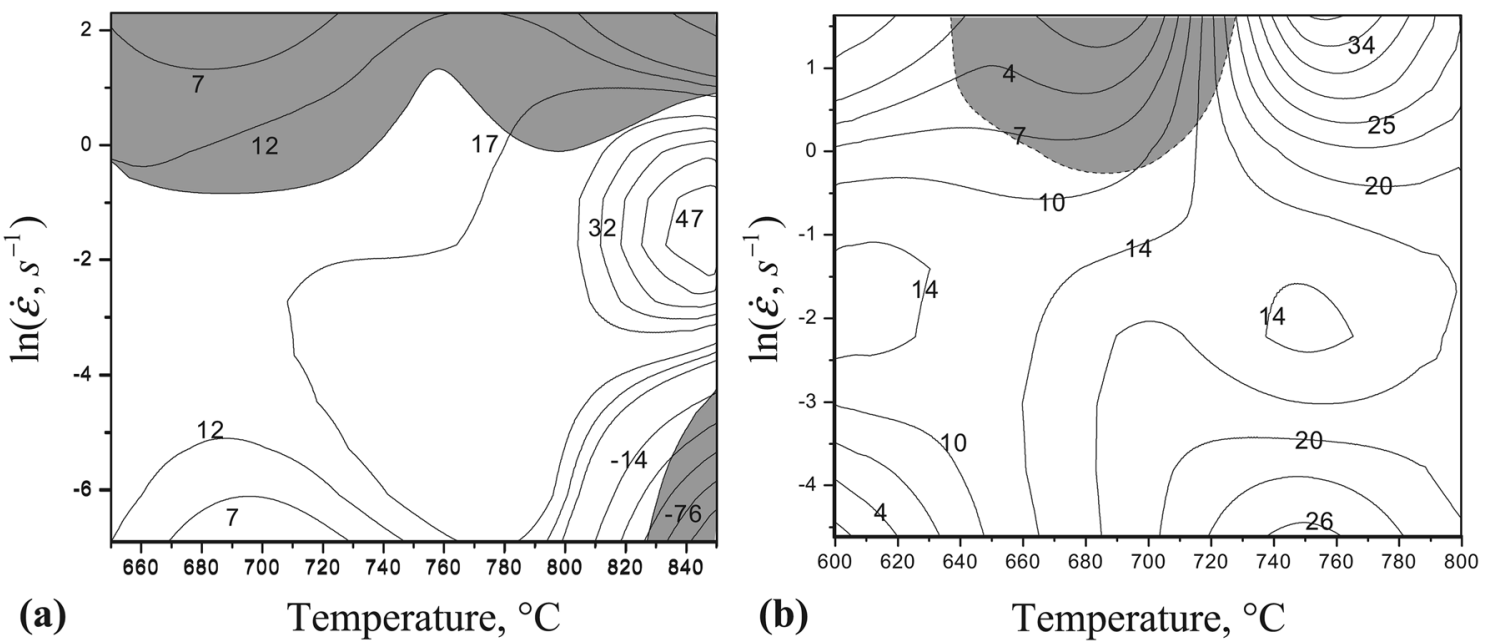

Fig. 5 Processing maps of (a) $\mathrm{Cu}-\mathrm{Cr}-\mathrm{Zr}$ and (b) $\mathrm{Cu}-\mathrm{Cr}-\mathrm{Zr}-\mathrm{Ce}$ alloys at 0.5 strain
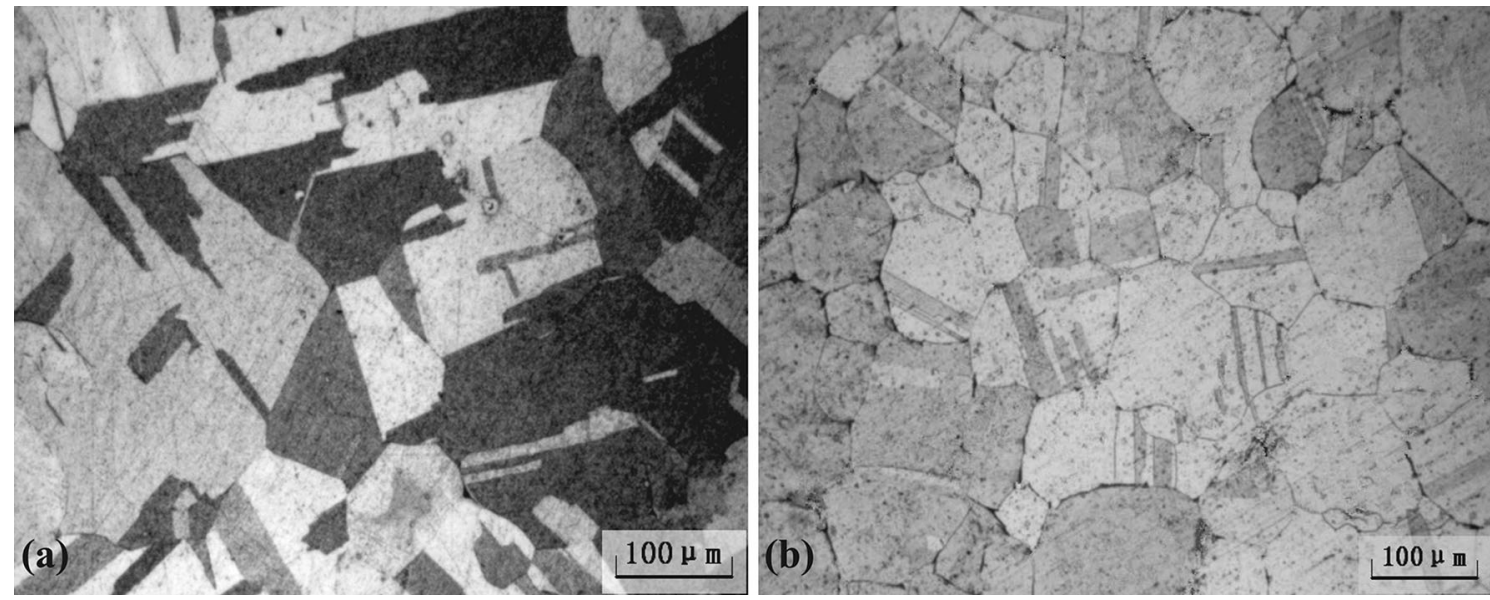

Fig. 6 Microstructure of (a) $\mathrm{Cu}-\mathrm{Cr}-\mathrm{Zr}$ and (b) $\mathrm{Cu}-\mathrm{Cr}-\mathrm{Zr}-\mathrm{Ce}$ alloys after solution treatment at $900{ }^{\circ} \mathrm{C}$ for $1 \mathrm{~h}$ 
To simplify the equation, one can take the natural logarithms of both sides of Eq 1:

$\ln \sinh \left(\alpha \cdot \sigma_{\mathrm{P}}\right)=-\frac{1}{n} \ln A+\frac{1}{n} \ln \dot{\varepsilon}+\frac{1}{n} \cdot \frac{Q}{R T}$.

$Q$ can be expressed as

$Q=\left.\left.R \frac{\partial \ln [\sinh (\alpha \sigma)]}{\partial(1 / T)}\right|_{\dot{\varepsilon}} \frac{\partial \ln \dot{\varepsilon}}{\partial \ln [\sinh (\alpha \sigma)]}\right|_{T}$.

Figure 2 and 3 display constitutive analysis of the $\mathrm{Cu}-\mathrm{Cr}-\mathrm{Zr}$ $\mathrm{Ce}$ alloy under various deformation conditions. Figure 2 is the variation between $\ln \dot{\varepsilon}$ and $\ln [\sinh (\alpha \sigma)]$ for the $\mathrm{Cu}-\mathrm{Cr}-\mathrm{Zr}$ Ce alloy at different temperatures. It clearly shows different slopes at varying temperature. According to $\mathrm{Eq} \mathrm{2,} n$ is the line slope in Fig. 2, while $Q / n R$ is the line slope in Fig. 3. Based on these slopes and $\mathrm{Eq} 1, n$ and $Q$ for the $\mathrm{Cu}-\mathrm{Cr}-\mathrm{Zr}$ Ce alloy can be calculated, respectively as $n=9.51$, $A=e^{54.1}, \alpha=0.011$, and $Q=495.8 \mathrm{~kJ} / \mathrm{mol}$. Figure 4 shows the relationship between the peak stress and the Zener-Hollomon parameter, $Z$. By substituting these values, one can get the constitutive equation for the hot deformation of the $\mathrm{Cu}$ Cr-Zr-Ce alloy:

$\dot{\varepsilon}=e^{54.1}[\sinh (0.011 \sigma)]^{9.51} \exp \left(-\frac{495.8}{R T}\right)$.

Using $A=e^{38.4}, n=7.56, \alpha=0.016$ and $Q=392.5 \mathrm{~kJ} / \mathrm{mol}$, the constitutive equation for the $\mathrm{Cu}-\mathrm{Cr}-\mathrm{Zr}$ alloy can also be obtained:
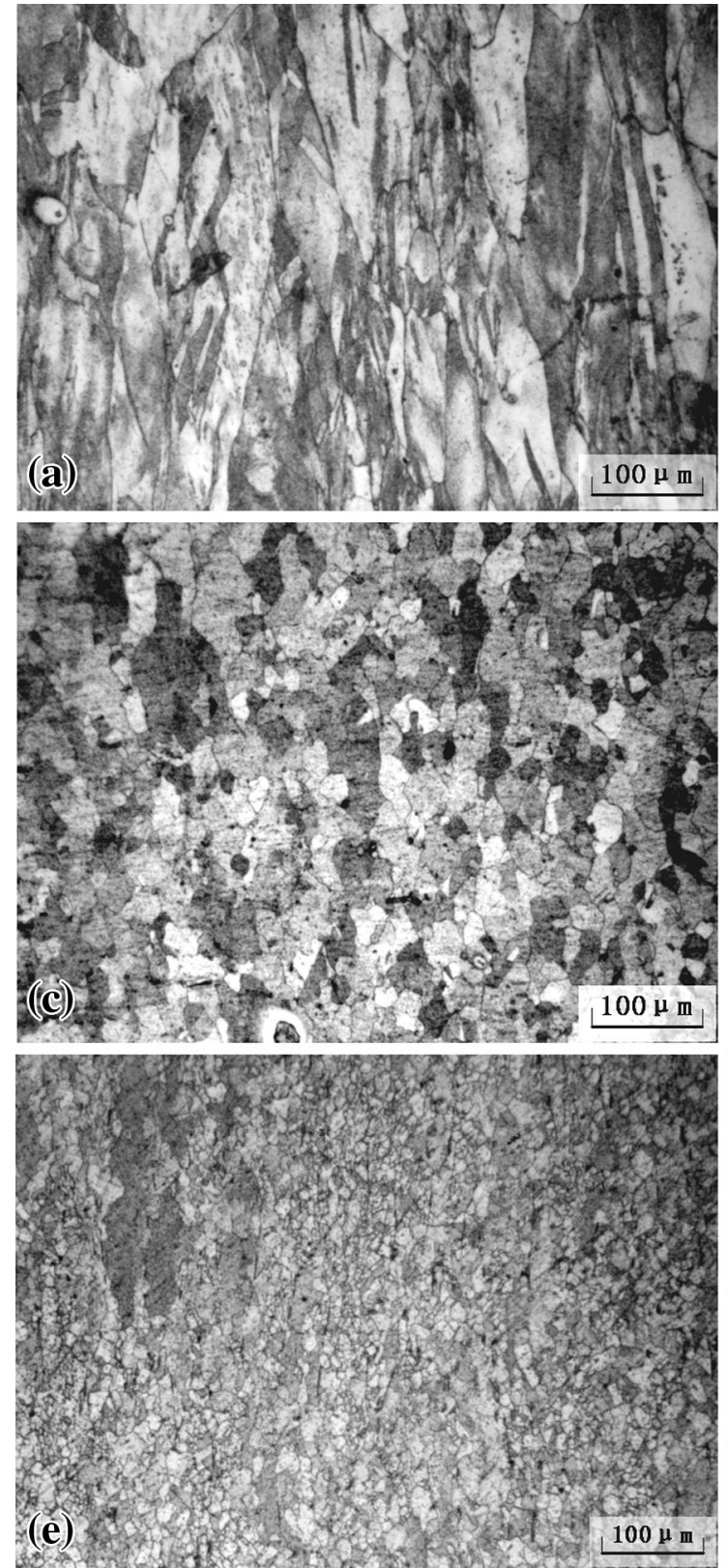
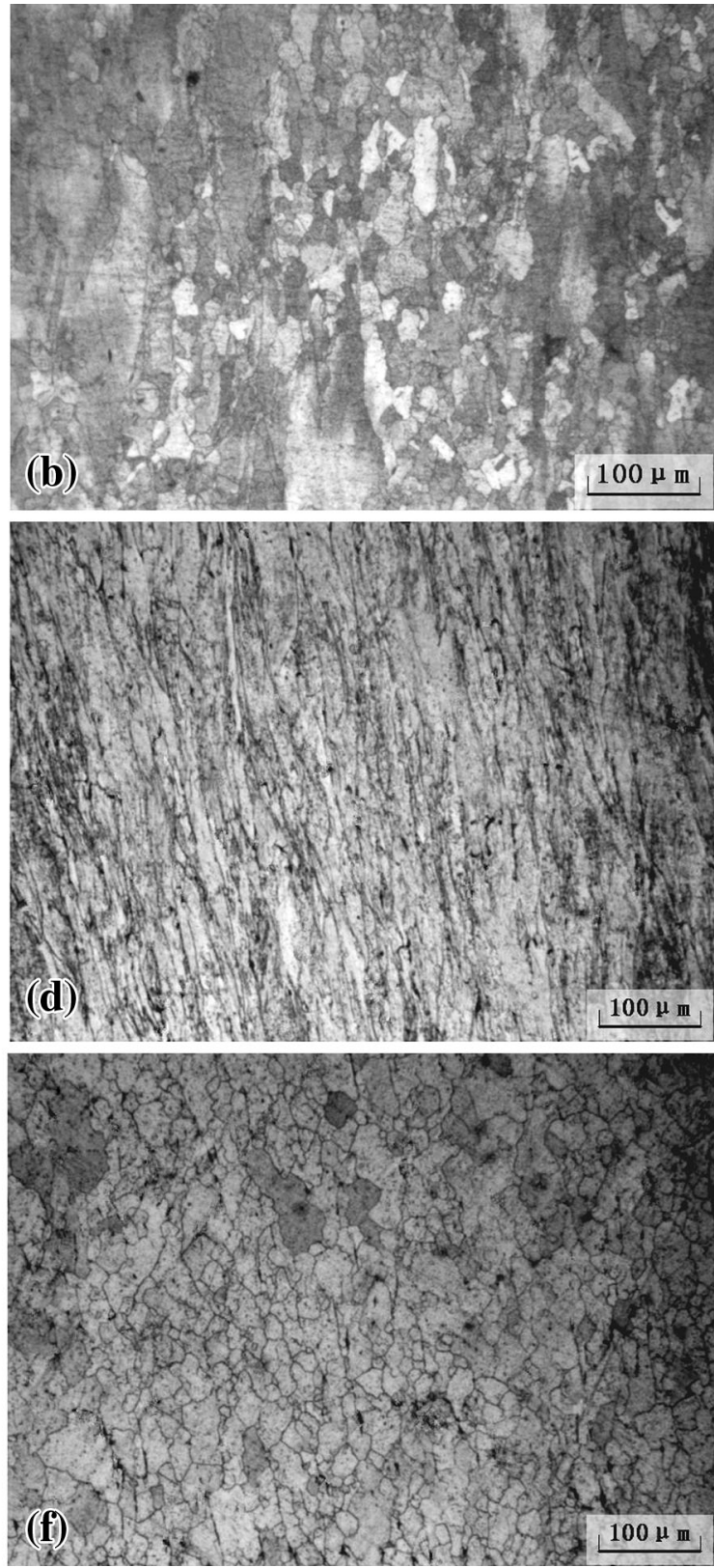

Fig. 7 Microstructure of (a-c) $\mathrm{Cu}-\mathrm{Cr}-\mathrm{Zr}$ and (d-f) $\mathrm{Cu}-\mathrm{Cr}-\mathrm{Zr}-\mathrm{Ce}$ alloys hot deformed at different conditions: (a) $650{ }^{\circ} \mathrm{C}$ and $1 \mathrm{~s}^{-1}$; (b) $850{ }^{\circ} \mathrm{C}$ and $1 \mathrm{~s}^{-1}$; (c) $850{ }^{\circ} \mathrm{C}$ and $0.1 \mathrm{~s}^{-1}$; (d) $600{ }^{\circ} \mathrm{C}$ and $1 \mathrm{~s}^{-1}$; (e) $750{ }^{\circ} \mathrm{C}$ and $1 \mathrm{~s}^{-1}$; (f) $800{ }^{\circ} \mathrm{C}$ and $0.01 \mathrm{~s}^{-1}$ 


$$
\dot{\varepsilon}=e^{38.4}[\sinh (0.016 \sigma)]^{7.56} \exp \left(-\frac{392.5}{R T}\right) .
$$

Comparing the activation energy $Q$ of the $\mathrm{Cu}-\mathrm{Cr}-\mathrm{Zr}-\mathrm{Ce}$ and $\mathrm{Cu}-\mathrm{Cr}-\mathrm{Zr}$ alloys, it increased by $21 \%$ with the addition of $\mathrm{Ce}$. The copper matrix has lower stacking fault energy. While dislocation climb and cross-slip are difficult to offset, $\mathrm{Ce}$ addition can effectively fix dislocations, hindering their motion. The energy for dislocation climb and cross-slip needs further improvement. The diffusion rate of atoms along the grain boundary is much faster than the interior of the grains at high temperature. The $\mathrm{Ce}$ is distributed at the grain boundary or sub-grain boundary. It can fix dislocations at the grain boundary and maintain high dislocation density. Thus, the addition of Ce can increase the deformation activation energy with more difficult dynamic recovery. However, dynamic recrystallization occurs easier. Comparing the constitutive equations for the $\mathrm{Cu}-\mathrm{Cr}-\mathrm{Zr}-\mathrm{Ce}$ and $\mathrm{Cu}-\mathrm{Cr}-\mathrm{Zr}$ alloys, the addition of $\mathrm{Ce}$ can improve the $Z$ parameter by an order of magnitude.

\subsection{Processing Maps}

The processing maps are constructed using the dynamic material model principles, which have been reviewed by Prasad and Srinivasan (Ref 19, 20). In this model, it is considered that the work piece undergoing hot deformation dissipates power, and the instantaneous power dissipated can be separated into two complementary parts: the $G$ content (temperature rise) and the $J$ content (microstructure mechanisms). The power dissipation capacity of the material can be evaluated by the efficiency of power dissipation, $\eta$, which is expressed in terms of the strain rate sensitivity parameter, $m$ :

$\eta=\frac{J}{J_{\max }}=\frac{2 m}{m+1}$

where $m=\frac{d J}{d G}=\frac{\dot{\varepsilon} d \sigma}{\sigma d \dot{\varepsilon}} \cong \frac{d \log \sigma}{d \log \dot{\varepsilon}}$.

The variation of $Z$ with the temperature, $T$, and the strain, $\varepsilon$, represents the relative value of the energy dissipation occurring through microstructure changes, and constitutes a processing map. Further, the extremum principles of irreversible thermodynamics, as applied to continuum mechanics of large plastic flow, are explored to define a criterion for the flow instability onset. This is expressed by the instability parameter $\xi(\dot{\varepsilon})$ :

$\xi(\dot{\varepsilon})=\frac{\partial \log \frac{m}{m+1}}{\partial \log \dot{\varepsilon}}+m<0$.

The variation of $\xi(\dot{\varepsilon})$ with temperature and the strain rate constitutes the unstable map, which can be superimposed on the processing map to delineate instability regimes of the negative $\xi(\dot{\varepsilon})$ values.

The processing maps of the $\mathrm{Cu}-\mathrm{Cr}-\mathrm{Zr}-\mathrm{Ce}$ and $\mathrm{Cu}-\mathrm{Cr}-\mathrm{Zr}$ alloys deformed at the strain of 0.5 were obtained, shown in Fig. 5. In Fig. 5 the unstable regions are represented by the shaded domains and the contour lines express the efficiency of power dissipation. With the increase of deformation temperature or the decrease of the strain rate, the power dissipation efficiency increases. When the strain is 0.5 , the $\mathrm{Cu}-\mathrm{Cr}-\mathrm{Zr}$ alloy exhibits two instability domains as follows: one in the 650$850{ }^{\circ} \mathrm{C}$ deformation temperature and $1-10 \mathrm{~s}^{-1}$ strain rate range, and another one in the $820-850{ }^{\circ} \mathrm{C}$ deformation temperature and $0.0001-0.001 \mathrm{~s}^{-1}$ strain rate range. At the same strain, the
$\mathrm{Cu}-\mathrm{Cr}-\mathrm{Zr}-\mathrm{Ce}$ alloy exhibits one instability domain as follows: the deformation temperature of $630-750{ }^{\circ} \mathrm{C}$ and the strain rate of $1-5 \mathrm{~s}^{-1}$. During practical application, it is necessary to stay away from this domain and the corresponding processing parameters.

Comparing the processing maps of the $\mathrm{Cu}-\mathrm{Cr}-\mathrm{Zr}-\mathrm{Ce}$ and $\mathrm{Cu}-$ $\mathrm{Cr}-\mathrm{Zr}$ alloy, the addition of $\mathrm{Ce}$ can significantly reduce the instability domains. It can be hot worked almost in the entire range of temperature and strain rates. The addition of $\mathrm{Ce}$ can optimize the hot working performance of the $\mathrm{Cu}-\mathrm{Cr}-\mathrm{Zr}$ alloy.

Figure 6 shows the microstructure of the $\mathrm{Cu}-\mathrm{Cr}-\mathrm{Zr}$ and $\mathrm{Cu}-$ $\mathrm{Cr}-\mathrm{Zr}-\mathrm{Ce}$ alloys after solution treatment, where Ce addition can evidently refine the grain. The average grain size of $\mathrm{Cu}-\mathrm{Cr}-\mathrm{Zr}$ and $\mathrm{Cu}-\mathrm{Cr}-\mathrm{Zr}-\mathrm{Ce}$ alloy is $87 \pm 1.2$ and $75 \pm 1.1 \mu \mathrm{m}$, respectively. An optical image of the microstructure of the $\mathrm{Cu}-\mathrm{Cr}-\mathrm{Zr}$ alloy deformed at $650{ }^{\circ} \mathrm{C}$ with the strain rate of $1 \mathrm{~s}^{-1}$ is shown in Fig. 7(a) as an example. There is only the shear zone without dynamic recrystallization grains. Figure 7(b) shows the $\mathrm{Cu}-\mathrm{Cr}$ $\mathrm{Zr}$ alloy microstructure deformed at $850{ }^{\circ} \mathrm{C}$ with the strain rate of $1 \mathrm{~s}^{-1}$. The nucleation of dynamic recrystallization occurred in some regions with high energy, such as grain boundaries, deformation bands, and twining grain boundaries. A lot of fine dynamic recrystallization grains showed up in the grain boundaries. Figure 7(d) shows the $\mathrm{Cu}-\mathrm{Cr}-\mathrm{Zr}-\mathrm{Ce}$ alloy deformed at $600{ }^{\circ} \mathrm{C}$ with the strain rate of $1 \mathrm{~s}^{-1}$, also exhibiting only the shear zone. Figure 8 is the TEM image of the microstructure of the $\mathrm{Cu}-\mathrm{Cr}-\mathrm{Zr}-\mathrm{Ce}$ alloy deformed at $600{ }^{\circ} \mathrm{C}$ with the strain rate of $1 \mathrm{~s}^{-1}$. It can be seen that the grains are elongated and there are no dynamic recrystallization grains. The dislocation tangles appear on the grain boundary. The microstructure of the $\mathrm{Cu}-\mathrm{Cr}-$ $\mathrm{Zr}$ and $\mathrm{Cu}-\mathrm{Cr}-\mathrm{Zr}-\mathrm{Ce}$ alloys deformed at $850{ }^{\circ} \mathrm{C}$ with the strain rate of $0.1 \mathrm{~s}^{-1}$ and at $800{ }^{\circ} \mathrm{C}$ with the strain rate of $0.01 \mathrm{~s}^{-1}$ is shown in Fig. 7(c) and (f), respectively. The microstructure of the deformed alloy is completely recrystallized, showing uniform and fine recrystallized grains. It can be seen from Fig. 7 that the optimized conditions for hot deformation of the $\mathrm{Cu}-\mathrm{Cr}-\mathrm{Zr}$ alloy are at a temperature range of $750-800{ }^{\circ} \mathrm{C}$ and $\mathrm{a}$ strain rate range of $0.01-0.1 \mathrm{~s}^{-1}$. The optimal processing parameters for hot deformation of the $\mathrm{Cu}-\mathrm{Cr}-\mathrm{Zr}$-Ce alloy are in the $700-800{ }^{\circ} \mathrm{C}$ temperature range and $0.01-0.1 \mathrm{~s}^{-1}$ strain rate range. These results show that the additions of $\mathrm{Ce}$ can reduce

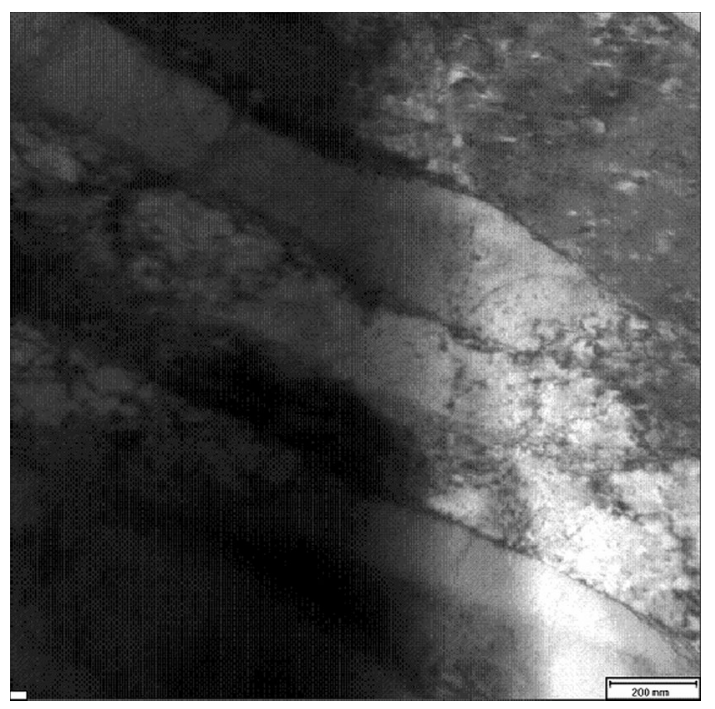

Fig. 8 TEM micrograph of the $\mathrm{Cu}-\mathrm{Cr}-\mathrm{Zr}-\mathrm{Ce}$ alloy microstructure 
the hot deformation temperature range of the $\mathrm{Cu}-\mathrm{Cr}-\mathrm{Zr}$ alloy under the same test conditions. The additions of Ce also can optimize the $\mathrm{Cu}-\mathrm{Cr}-\mathrm{Zr}$ alloy hot workability.

\section{Conclusions}

The addition of Ce improves the peak stress and deformation resistance of the $\mathrm{Cu}-\mathrm{Cr}-\mathrm{Zr}$ alloy during hot deformation. The constitutive equations for $\mathrm{Cu}-\mathrm{Cr}-\mathrm{Zr}$ and $\mathrm{Cu}-\mathrm{Cr}-\mathrm{Zr}-\mathrm{Ce}$ alloys were obtained by correlating the flow stress, strain rate, and temperature using regression analysis. The addition of $\mathrm{Ce}$ can improve the deformation activation energy and dynamic recrystallization is easier to occur. The optimal processing parameters for hot deformation of the $\mathrm{Cu}-\mathrm{Cr}-\mathrm{Zr}-\mathrm{Ce}$ alloy are in the $700-800{ }^{\circ} \mathrm{C}$ temperature range and the $0.01-0.1 \mathrm{~s}^{-1}$ strain rate range. The additions of $\mathrm{Ce}$ can evidently refine the grain and optimize the hot workability of the $\mathrm{Cu}-\mathrm{Cr}-\mathrm{Zr}$ alloy.

\section{Acknowledgments}

This work was supported by the National Natural Science Foundation of China (51101052) and the National Science Foundation (IRES1358088).

\section{References}

1. Y. Zhang, A.A. Volinsky, Q.Q. Xu, Z. Chai, B.H. Tian, P. Liu, and H.T. Tran, Deformation Behavior and Microstructure Evolution of the $\mathrm{Cu}-$ 2Ni-0.5Si-0.15Ag Alloy During Hot Compression, Metall. Mater. Trans. A, 2015. doi:10.1007/s11661-015-3150-7

2. C.D. Xia, Y.L. Jia, W. Zhang, K. Zhang, Q.Y. Dong, G.Y. Xu, and M. Wang, Study of Deformation and Aging Behaviors of a Hot RolledQuenched Cu-Cr-Zr-Mg-Si Alloy During Thermomechanical Treatments, Mater. Des., 2012, 39, p 404-409

3. H.Q. Li, S. Xie, X. Mi, Y. Liu, P.Y. Wu, and L. Cheng, Influence of Cerium and Yttrium on Cu-Cr-Zr Alloys, J. Rare Earths, 2006, 24(1), p 367-371

4. J.H. Su, Q.M. Dong, and P. Liu, Research on aging precipitation in a Cu-Cr-Zr-Mg alloy, Mater. Sci. Eng. A, 2005, 392(1-2), p 422-426

5. H.T. Tran, M.H. Shirangi, X. Pang, and A.A. Volinsky, Temperature, Moisture and Mode-mixity Effects on Copper Leadframe/EMC Interfacial Fracture Toughness, Int. J. Fract., 2013, 185, p 115-127
6. Z.W. Wu, J.D. Zhang, Y. Chen, and L. Meng, Effect of Rare Earth Addition on Microstructural, Mechanical and Electrical Characteristics of Cu-6\%Fe Microcomposites, J. Rare Earths, 2009, 27(1), p 8791

7. J.B. Correia, H.A. Davies, and C.M. Sellars, Strengthening in Rapidly Solidified Age Hardened CuCr and CuCrZr Alloys, Acta Mater., 1997, 45(1), p 177-190

8. L.M. Bi, P. Liu, X.H. Chen, X.K. Liu, W. Li, and F.C. Ma, Analysis of Phase in $\mathrm{Cu}-15 \% \mathrm{Cr}-0.24 \% \mathrm{Zr}$ Alloy, Trans. Nonferrous Met. Soc. China, 2013, 23(5), p 1342-1348

9. P. Hanzelka, V. Musilova, T. Kralik, and J. Vonka, Thermal Conductivity of a CuCrZr Alloy from $5 \mathrm{~K}$ to Room Temperatures, Cryogenics, 2010, 50(11-12), p 737-742

10. P.K. Jayakumar, K. Balasubramanian, and T.G. Rabindranath, Recrystallisation and Bonding Behaviour of Ultra Fine Grained Copper and Cu-Cr-Zr Alloy Using ECAP, Mater. Sci. Eng. A, 2012, 538(15), p 713

11. L. Zhang, Z. Li, Q. Lei, W.T. Qiu, and H.T. Luo, Hot Deformation Behavior of Cu-8.0Ni-1.8Si-0.15Mg Alloy, Mater. Sci. Eng. A, 2011, 528(3), p 1641-1647

12. S. Suzuki, N. Shibutani, and K. Mimura, Improvement in Strength and Electrical Conductivity of CuNiSi Alloy by Aging and Cold Rolling, $J$. Alloy. Compd., 2006, 417, p 116-120

13. H. Feng, H.C. Jiang, D.H. Yan, and L.J. Rong, Effect of Continuous Extrusion on the Microstructure and Mechanical Properties of a CuCrZr Alloy, Mater. Sci. Eng. A, 2013, 582(10), p 219-224

14. H. Zhang, H.G. Zhang, and L.X. Li, Hot Deformation Behavior of CuFe-P Alloys During Compression at Elevated Temperatures, J. Mater. Process. Technol., 2009, 209(6), p 2892-2896

15. Y.Q. Long, P. Liu, Y. Liu, W.M. Zhang, and J.S. Pan, Simulation of Recrystallization Grain Growth During Re-aging Process in the Cu-NiSi Alloy Based on Phase Field Model, Mater. Lett., 2008, 62, p 3039 3042

16. A. Momeni and K. Dehghani, Characterization of Hot Deformation Behavior of 410 Martensitic Stainless Steel Using Constitutive Equations and Processing Maps, Mater. Sci. Eng. A, 2010, 527, p 5467-5473

17. M. Morakabatia, S.H. Kheirandish, M. Aboutalebi, A. Karimi Taheri, and S.M. Abbasi, The Effect of $\mathrm{Cu}$ Addition on the Hot Deformation Behavior of NiTi Shape Memory Alloys, J. Alloys Compd., 2010, 499, p 57-62

18. M. Karami and R. Mahmudi, Hot Shear Deformation Constitutive Analysis and Processing Map of Extruded Mg-12Li-1Zn bcc Alloys, Mater. Des., 2014, 53, p 534-539

19. Y.V.R.K. Prasad and K.P. Rao, Processing Maps for Hot Deformation of Rolled AZ31 Magnesium Alloy Plate: Anisotropy of Hot Workability, Mater. Sci. Eng. A, 2012, 487(1-2), p 316-327

20. N. Srinivasan, Y.V.R.K. Prasad, and K.P. Rao, Hot Deformation Behavior of Mg-3Al Alloy Study Using Processing Map, Mater. Sci. Eng. A, 2008, 476(2), p 146-156 